\title{
Low birth weight and associated factors among singleton neonates born at Felege Hiwot referral hospital, North West Ethiopia
}

Teje Adane ${ }^{1}$, Berihun Assefa Dachew ${ }^{2}$

1. Beneshangul Gumuz Regional State, Zonal Health office, Ethiopia

2. Department of Epidemiology and Biostatistics, Institute of Public Heath, College of Medicine and Health Science, University of Gondar, Ethiopia.

Email addresses of authors

BA: berihunassefa21@gmail.com

TA: tejeadane524@gmail.com

\begin{abstract}
Background: Low birth weight is one of the public health problems in the globe and it is an indicator of the health of the newborn survival and the mother's nutrition and health status. This study was aimed to determine the prevalence of low birth weight and its associated factors among mothers who gave birth at Bahir Dar Felege Hiwot referral hospital.

Methods: A cross-sectional facility based study was conducted from March 18 to May 18 / 2015. A total of 662 mothers were included in the study.The data was entered and analyzed using SPSS version 20 software. Bivariate and multivariable logistic regression was used to identify factors associated with low birth weight.

Results: The prevalence of low birth weight was found to be 11.6\%. Age of the mothers (20-34 years) AOR $=0.4(95 \%$ CI: 0.19-0.93), low income AOR=2.6 (95\%CI: 1.16-6.05), gestational age < 37 weeks AOR=18.2 (95\% CI:9.26-35.94), MUAC<23 $\mathrm{cm}$ AOR $=3.4$ (95\%CI:1.38-8.60) and pregnancy induced hypertension AOR $=6.5$ (95\%CI:3.06-14.0) were factors associated with low birth weight.

Conclusion: The prevalence of low birth weight was in line with WHO estimate for sub-Saharan Africa. Nutritional counseling and early detection and management of pregnancy induced hypertension is recommended.
\end{abstract}

Keywords: Low birth weight, prevalence, Northwest Ethiopia.

DOI: https://dx.doi.org/10.4314/ahs.v18i4.42

Cite as: Adane T, Dachew BA. Low birth weight and associated factors among singleton neonates born at Felege Hiwot referral hospital, North West Ethiopia. Afri Health Sci. 2018;18(4): 1204-1213. https:/ / dx.doi.org/10.4314/abs.v18i4.42

\section{Background}

Low birth weight is defined by the (WHO) as the weight of an infant at birth of less than 2,500 grams. It can be further classified as very low birth weight (birth weight

\section{Corresponding author: \\ Berihun Assefa Dachew, Department of Epidemiology and Biostatistics, Institute of Public Heath, College of Medicine and Health Science, University of Gondar, Ethiopia. Email: berihunassefa21@gmail.com}

less than 1500 grams) and extremely low birth weight (which is less than $1000 \mathrm{gram})^{1}$

The global prevalence of low birth weight is $15.5 \%$, which means that more than 20 million such infants are born each year from 130 million annual births. Low birth weight remains a major public health problem in developing countries and contributes to $60-80 \%$ infant mortality. Of 20 to 25 million babies born each year globally, nearly $93 \%$ of them are in developing countries ${ }^{2}$. The incidence of low birth weight in sub-Saharan African countries was estimated to be $13 \%$ to $15 \%{ }^{3}$. Studies revealed that the prevalence of low birth weight in Ethiopia ranges from $8.4 \%$ to $28.3 \%{ }^{3-6}$.

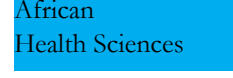
(C) 2018 Adane et al. Licensee African Health Sciences. This is an Open Access article distributed under the terms of the Creative commons Attribution
License (https://creativecommons.org/licenses/BY/4.0), which permits unrestricted use, distribution, and reproduction in any medium, provided the original work is properly cited. 
Preterm birth and growth restriction are the two main factors associated with low birth weight. Other factors associated with low birth weight include maternal age, pre-pregnancy weight, maternal under nutrition, vitamin and mineral deficiencies, maternal disease and infections during pregnancy ${ }^{3,5,7-9}$.

Reducing the incidence of low birth weight by at least one third between 2000 and 2010 was a major goal of "A World Fit for Children" program of the United Nations ${ }^{7}$. However, low birth weight is still a major public health problem for developing countries; greatly contributing to neonatal and child mortality. It is an indicator of new born survival and also an indicator of mother's nutrition and health status ${ }^{2,6}$. However, there are limited researches in Ethiopia in general and no study in the study area which determines the prevalence of low birth weight and its associated factors. Therefore, this study amied to determine the prevalence of low birth weight and its associated factors among singleton births at Felege Hiwot referral hospital, North West Ethiopia. The findings from this study will provide information for planners and policy makers which target on designing reduction of low birth weight in the area.

\section{Methods}

Study setting: Bahir Dar is the capital city in Amhra region located $549 \mathrm{~km}$ away from Addis Ababa, the Capital city of Ethiopia. Bahir Dar Special Zone is one of the eleven zones in the Amhara Regional State, which is located in the North Western part of Ethiopia. According to the Ethiopian National census report, the total population of the Zone is 220,384; of this 180,094 (81.7\%) people are urban dwellers while 40,250 (18.3\%) people are rural dwellers. Out of the total population 122,077 are females with a pregnancy rate of $3.7 \%$, which implies the total number of expected pregnant women in a given year is $12,200^{8}$. The study was conducted in Felge- Hiwot Referral Hospital, which is a public referral hospital in Bahir Dar City.

Study design and period: Institutional based cross-sectional study was conducted to determine prevalence of low birth weight and its associated factors in Bahir Dar Felge- Hiwot Referral Hospital from March 18 to May $18 / 2015$.

Study population: All mothers who gave birth in Bahir Dar referral hospital during the study period were the study population for this study. All live newborns delivered at Feleg Hiwot Referral Hospital during the study period were included in the study, while newborns with major congenital anomalies, and twins or multiple births were excluded from the study.

Sample size: Sample size was determined using by single proportion formula with the assumption of $17 \%$ proportion (similar study in NorthWest Ethiopia) ${ }^{9}, 95 \%$ confidence level (z) and marginal error (d) of 3\%

$\mathrm{n}=\mathrm{Z}^{2 *} \mathrm{p}(1-\mathrm{p}) / \mathrm{d}^{2}$

With this assumption the sample size was 602. Considering 10\% non response rate the final sample size was 662 . We also considred the second objective while determining our sample size, but prevalence estimate was used for sample size calculation since it gave a maximum figure (662) which can address both study objectives.

Systematic random sampling technique was used to select study participants and data was collected every other delivery for two months duration.

Variables: Low birth weight was an outcome variables for this study while independent variables included socio-demographic factors (like maternal age, residence, marital status, occupational status, educational status, average monthly income and sex of the neonate), maternal nutrition related factors (hemoglobin level, iron supplement, weight of the mother, height, MUAC, pre-pregancy BMI, and meal frequency), maternal morbidity (pregnancy induced hypertension, malaria and HIV status and anemia), obstetric factors (numbers of ANC visit, ANC starting time, parity, gravidity, birth interval and bad obstetric history) and behavioral factors (cigarette smoking and alcohol consumption).

\section{Data collection tools and procedures:}

Data was collected using pre-tested and structured questionnaire. The instrument was pre-tested and the reliability of the tool was checked using Cronbach's alpha reliability test with a score of 0.8 . The data were collected by 2 diploma female trained nurses and 1 female degree holder nurse supervisor. One day training was given for data collectors and the supervisor. The data collectors took the weight of the newborn within 1 hour after delivery. The newborns were weighted naked using a digital scale. Data collectors and facilitators were under close supervision and the collected data were reviewed and 
checked for completeness, clarity and accuracy on a daily basis prior to data entry.

Data processing and analysis: The collected data were coded, entered by using EPI-INFO version 7 software and analyzed using SPSS version 20. Descriptive statistics like percentages, proportions, mean and standard deviation was used. The result was presented in tables and texts. Bivariate and multivaraible analysis logistic regression anlyses were performed to identify factors associated with low birth weight. A p-value of 0.2 was used as a screening criterion for including variables in the multivariable model. $\mathrm{P}$ - Values less than 0.05 were considered statistically significant. Model fitness was checked using Hosmer and Lemeshow goodness of a fit test.
Ethical consideration: Ethical clearance was obtained from the Institutional Review Board of Bahir Dar University. Written informed consent was also obtained from the study subjects. Confidentiality was maintained at all levels.

\section{Results}

\section{Socio-demographic characteristics}

From 662 sampled populations, 647 were participated in the study with a response rate of $97.7 \%$. The mean age of respondents was $26.3 \pm 5.5$ years and $304(47 \%)$ of respondents were in the age group of 20-34 years. Five hundred ten $(78.8 \%)$ of the participants were urban dwellers (Table 1).

Table 1. Socio-Demographic characteristics of Respondents at Felege Hiwot referral hospital, North West Ethiopia $(n=647)$

\begin{tabular}{lll}
\hline Variable & Frequency & Percent \\
\hline Age of mothers & & \\
$<20$ & 53 & 8.2 \\
$20-34$ & 510 & 78.8 \\
$\begin{array}{l}\text { R5-49 } \\
\text { Residence }\end{array}$ & 84 & 13 \\
Rural & & \\
Urban & 272 & 42 \\
Religion & 375 & 58 \\
Orthodox & & \\
Muslim & 591 & 91.3 \\
Protestant & 50 & 7.7 \\
Marital status & 6 & 0.9 \\
Married & & \\
Divorced & 638 & 98.6 \\
Educational status & 9 & 1.4 \\
Cannot read and write & & \\
Elementary(1-8) & 265 & 41 \\
secondary and certificate & 107 & 16.5 \\
Diploma and above & 140 & 21.6 \\
Occupational status & 135 & 20.9 \\
House wife & & \\
Employee & 481 & 74.3 \\
Merchant & 111 & 16.7 \\
Student & 31 & 4.8 \\
Daily labourer \\
Average monthly income \\
(USD)
\end{tabular}


Obstetric characteristics of mothers

Among the participants $347(53.6 \%)$ were primiparas and
$171(26.7 \%)$ of the mothers had a history of cesarean section delivery. Around $95 \%$ of the mothers had at least one antenatal care visit (Table 2).

Table 2. Obstetric characteristics of respondents at Felege Hiwot referral hospital, North West Ethiopia, (n= 647)

\begin{tabular}{lll}
\hline Variable & Frequency & Percent \\
\hline Gravida & 332 & \\
$\geq$ & 315 & 51.3 \\
II & 347 & 48.7 \\
$\mid$ & 300 & 53.6 \\
$\geq$ II & & 46.4 \\
History of abortion & 40 & \\
Yes & 607 & 6.2 \\
No & & 93.8 \\
Birth interval (n=315) & 31 & \\
$<2$ years & 284 & 9.8 \\
$\geq 2$ years & & 90.2 \\
History of C/S & 171 & \\
Yes & 476 & 26.7 \\
No & & 73.6 \\
Time of first ANC & 150 & \\
In the first 3 months & 437 & 23.2 \\
3-6 month & 27 & 67.5 \\
6-9 month & 33 & 4.2 \\
Not attained ANC & & 5.1 \\
Number of ANC visit & 11 & 1.8 \\
Once & 42 & 6.8 \\
Two & 111 & 18.1 \\
Three & 450 & 73.3 \\
Four & & \\
\hline CS =Cesarean section, ANC= Antenatal care &
\end{tabular}

Nutritional status of mothers

Of the respondents, $77.3 \%$ mothers received ferrous sulfate supplementation while they are pregnant. From those around $30 \%$ of the mothers took for less than one month. Mean height and Mid-upper arm circumference (MUAC) of the respondents were $155.8 \pm 6.4 \mathrm{~cm}$ and $23.5 \pm 2.6 \mathrm{~cm}$ respectively Table 3 . 
Table 3. Nutritional characteristics of respondents at Felege Hiwot referral hospital, North West Ethiopia, 2015 ( $n=647)$

\begin{tabular}{lll}
\hline Variable & Frequency & Percent \\
\hline Height of mothers in cm & & \\
$<150$ & 101 & 15.6 \\
$\geq 150$ & 546 & 84.4 \\
$\begin{array}{l}\text { Mid-upper arm circumference } \\
<23 \mathrm{~cm}\end{array}$ & 350 & .54 .1 \\
$23-25 \mathrm{~cm}$ & 131 & 20.3 \\
$>25 \mathrm{~cm}$ & 166 & 25.6 \\
BMl (kg/m $\left.{ }^{2}\right)$ & & \\
$<18.5$ & 155 & 24 \\
$18.5-24.9$ & 419 & 64.7 \\
$>25$ & 73 & 11.3 \\
Nutritional counseling & & \\
Yes & 411 & 63.5 \\
No & 236 & 36.5 \\
Frequency of meal/day & & \\
two times & 59 & 9.1 \\
three times & 396 & 61.2 \\
$\geq$ four times & 192 & 29.7 \\
Ferrous sulphate intake & & \\
Yes & 506 & 78.2 \\
No & 141 & 21.8 \\
Hemoglobin level & & 5.9 \\
$<11 \mathrm{~g} / \mathrm{dl}$ & 38 & 94.1 \\
$\geq 11 \mathrm{~g} / \mathrm{dl}$ & 609 & \\
\hline
\end{tabular}

Maternal morbidity

Among the total mothers who gave birth during the study period, $47(7.2 \%)$ had pregnancy induced hypertension, and $46(7.1 \%)$ had malaria, $27(4.17 \%)$ had anemia, 6 $(0.92 \%)$ had HIV/AIDS and $5(0.77 \%)$ had asthma.
Prevalence of low birth weight

The prevalence of low birth weight was found to be 75 $(11.6 \%)$ (Figure 1). The mean birth weight of the newborns was $2907.7 \pm 518.4 \mathrm{gm}$. While the minimum weight was 1000 grams, the maximum was 5000 grams. Forty two $(56 \%)$ of the low birth weight babies were term $(>37$ weeks of gestational age). 


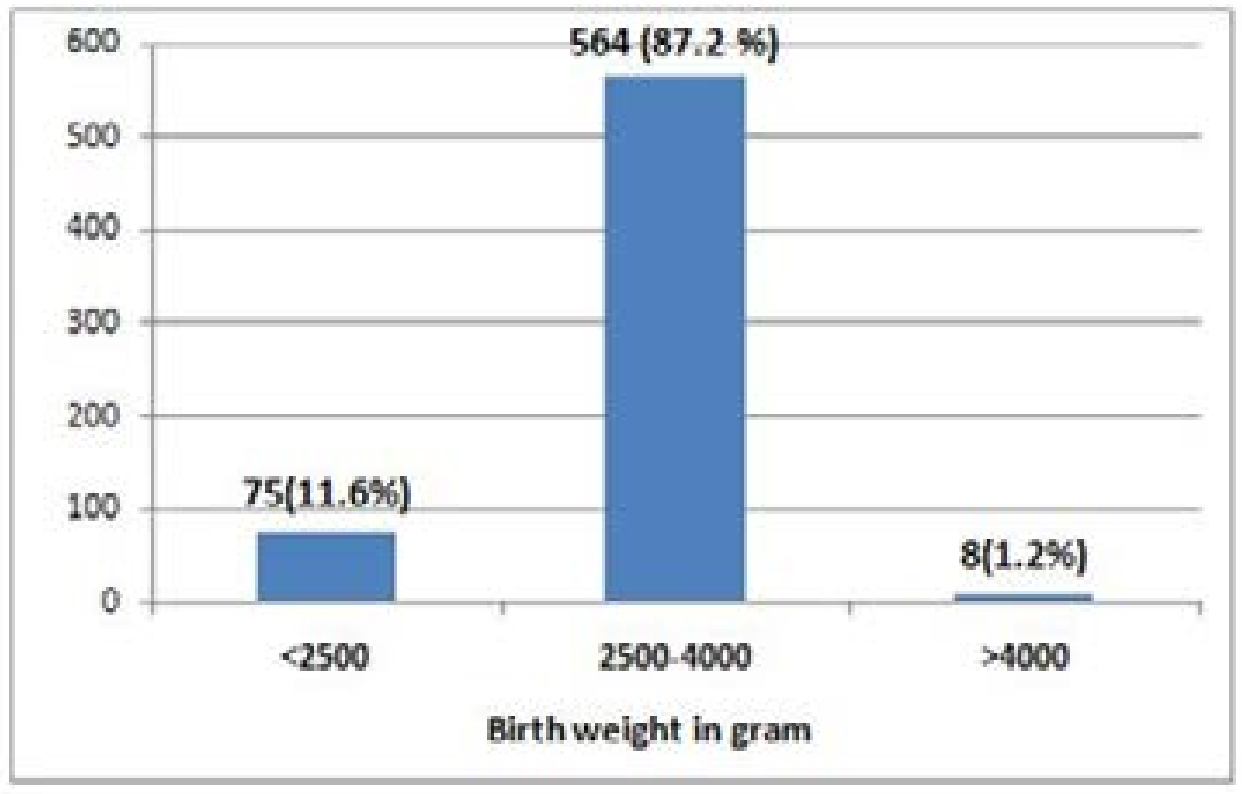

Figure 1. Birth Weight among neonates born at Felege Hiwot referral hospital, North West Ethiopia, 2015 ( $n=647$ ).

Proportion of low birth weight by maternal and neonatal characterstics

The prevalence of low birth weight among male new- borns was $53.3 \%$ and more than half $(56 \%)$ of the low birth weight babies were term ( $>37$ weeks of gestational age) (Table 4). 
Table 4. Proportion of Low birth weight by child sex, maternal age, gestational week, maternal mid upper um circumference (MUAC) and pregnancy induced hypertension

\begin{tabular}{|c|c|c|}
\hline Variables & Number & Percent \\
\hline \multicolumn{3}{|l|}{ Sex of baby } \\
\hline Male & 40 & 53.3 \\
\hline Female & 35 & 46.7 \\
\hline \multicolumn{3}{|c|}{$\begin{array}{l}\text { Maternal age (in } \\
\text { years) }\end{array}$} \\
\hline$<20$ & 16 & 21.3 \\
\hline $20-34$ & 45 & 60 \\
\hline $35-49$ & 14 & 18.7 \\
\hline \multicolumn{3}{|l|}{$\begin{array}{l}\text { Gestational } \\
\text { week }\end{array}$} \\
\hline $\begin{array}{l}<37 \text { weeks of } \\
\text { gestation }\end{array}$ & 33 & 44 \\
\hline \multicolumn{3}{|l|}{$\begin{array}{l}\text { gestation } \\
\text { MUAC (in CM) }\end{array}$} \\
\hline$<23$ & 56 & 74.7 \\
\hline $23-25$ & 13 & 17.3 \\
\hline$>25$ & 6 & 8 \\
\hline \multirow{2}{*}{\multicolumn{3}{|c|}{$\begin{array}{l}\text { Pregnancy } \\
\text { induced } \\
\text { hypertension }\end{array}$}} \\
\hline & & \\
\hline Yes & 19 & 25.3 \\
\hline No & 56 & 74.7 \\
\hline
\end{tabular}

Factors associated with low birth weight

The bivariate analysis showed that pregnant mothers who were residing in a rural area, having $\mathrm{Hgb}$ level $<11 \mathrm{~g} / \mathrm{dl}$ and body mass Index less than $18.5 \mathrm{~kg} / \mathrm{m}^{2}$ were factors associated for Low birth weight. However; after adjusting the potential confounders: Age of the mother (20-34 years) AOR 0.4 (95\% CI: 0.19-0.93), low income (AOR= 2.6 (95\%CI: 1.16-6.05)), gestational age <37weeks $\mathrm{AOR}=18.2$. (95\%CI: 9.26-35.94), mid upper arm circumference $(\mathrm{MUAC})<23 \mathrm{~cm}$ AOR 3.4 (95\% CI: 1.38-8.60) and Pregnancy induced hypertension AOR $=6.5(95 \% \mathrm{CI}$ : 3.06-14.00) were factors associated with low birth weight (Table 5). 
Table 5: Factors associated with low birth weight among singleton neonates born at FelegeHiwot referral hospital $(n=647)$

\begin{tabular}{|c|c|c|c|c|}
\hline \multirow[t]{2}{*}{ Variables } & \multicolumn{2}{|c|}{ Low birth weight } & \multirow{2}{*}{$\begin{array}{l}\text { Crude Odds } \\
\text { Ratio (COR) }\end{array}$} & \multirow{2}{*}{$\begin{array}{l}\text { Adjusted Odds } \\
\text { Ratio (AOR) }\end{array}$} \\
\hline & No & Yes & & \\
\hline \multicolumn{5}{|l|}{ Residence } \\
\hline Rural & 227 & 45 & $2.3(1.40-3.42)$ & $1.3(0.71-2.50)$ \\
\hline Urban & 345 & 30 & 1 & 1 \\
\hline \multicolumn{5}{|l|}{ Age of mother } \\
\hline$<20$ & 37 & 16 & 2.2.(0.954.91) & $1.6(0.59--4.31)$ \\
\hline $20-34$ & 465 & 45 & $0.5(0.250 .93)$ & $0.4(0.19-0.93)^{*}$ \\
\hline $35-49$ & 70 & 14 & (9) & 1 \\
\hline \multicolumn{5}{|l|}{ Income (USD) } \\
\hline$<75$ & 126 & 33 & $2.9(1.50-5.91)$ & $2.6(1.16-6.05)^{\star}$ \\
\hline $75-175$ & 298 & 29 & $1.1(0.55-2.19)$ & $1.2(0.56-4.31)$ \\
\hline$\geq 175$ & 148 & 13 & 1 & 1 \\
\hline \multicolumn{5}{|l|}{ Gestational week } \\
\hline$<37$ weeks & 28 & 33 & $15.3(8.43-27.63$ & $18.2(9.26-35.94)^{*}$ \\
\hline$\geq 37$ weeks & 544 & 42 & res & 1 \\
\hline \multicolumn{5}{|l|}{ Hgb level } \\
\hline$<11 \mathrm{~g} / \mathrm{dl}$ & 28 & 10 & $2.9(1.38-6.43)$ & $2.5(0.92-6.71)$ \\
\hline$>11 \mathrm{~g} / \mathrm{dl}$ & 544 & 65 & 1 & 1 \\
\hline \multicolumn{5}{|l|}{$\begin{array}{l}\text { Pre pregnancy } \\
\mathrm{BMI} \mathrm{Ka} / \mathrm{m}^{2}\end{array}$} \\
\hline$<18.5 \mathrm{Kg} / \mathrm{m}^{2}$ & 122 & 29 & $2.65(1.04-6.75)$. & $2.5(0.9-4.92)$ \\
\hline $18.5-24.9 \mathrm{Kg} / \mathrm{m}^{2}$ & 383 & 40 & $1.16(0.5-2.82)$ & $2.5(0.74-4.40)$ \\
\hline \multicolumn{5}{|l|}{ MUAC } \\
\hline$<23$ & 294 & 56 & $3.3(1.40-7 . .96)$ & $3.4(1.38-8.60)^{*}$ \\
\hline $23-25$ & 173 & 13 & $1.3(0.49-3.57)$ & $2.1(0.71-6.37)$ \\
\hline$>25$ & 105 & 6 & 1 & 1 \\
\hline \multicolumn{5}{|l|}{ PIH } \\
\hline Yes & 33 & 19 & $5.5(2.96-10.38)$ & $6.5(3.06-14.00)^{*}$ \\
\hline No & 539 & 56 & 1 & 1 \\
\hline
\end{tabular}

\section{Discussion}

The prevalence of low birth weight was $11.6 \%$ in the current study, which is in line with Ethiopian demographic and health survey reports of 2011 in Amhara region $11.2 \%$, though EDHS used maternal self-reports to measure lower birth weight leading to biased estimate ${ }^{10}$. Similar findings were also obtained in Iran $11.1 \%{ }^{11}$ and Tamilnadu $11.67 \%{ }^{12}$. However; this finding is lower than in a study done in Gondar, Ethiopia $17.4 \%{ }^{3,13}$ and Northern
India $32.3 \%{ }^{14}$. The possible reason for this difference might be due to time variation and / or difference in the nutritional status of the mother. Moreover, mothers with multiple pregnancies were included in those studies which may overestimate the prevalence.

The current prevalence is higher than study done in Axum, Ethiopia $9.9 \% 0^{4}$, Brazil 7.6\% ${ }^{15}$ and, Western Algeria $5.53 \%{ }^{16}$. The possible explanation for observed difference may be time difference, difference in geographic 
area, accessed to adequate nutrient before and after conception, health service utilizations, quality of health service, dietary counseling for pregnant mothers and study design difference between our study and others.

In this study, mothers whose age was between 20 to 34 years old had less risk to have low birth weight as compared to age 35 years. Those mothers with the age range of 20-34 years had $60 \%$ less risk of giving birth to a low weight baby as compared to those whose age was 35 years and above $(\mathrm{AOR}=0.4$ (95\%CI:0.19-0.93). This finding is supported by the studies done in Ghana and Qatar $^{17,18}$. This may be due to the fact that mothers with old age have depletion of nutrition by previous birth.

In this study, lowest monthly income was significantly associated with low birth weight. Mothers who had monthly income less than 70 USD were three times $(A O R=2$. $6(95 \% \mathrm{CI}=1$. 16-6.05) more likely to have a low birth weight baby than those who had greater than 175 USD. This finding is supported by the studies in Nepal, Japan and India ${ }^{19-22}$. This is due to the fact that in order to reduce low birth weight two extra meals are required in addition to the basic three meals. However, mothers with low monthly income may not get adequate nutrition. For example, in this study, $9 \%$ of the rural mothers did not have access to more than two meals per day, leading to the maternal under nutrition and in turn low birth weight. Gestational age less than 37 weeks was significantly associated with low birth weight in this study. Those who gave birth before 37 weeks gestational age (per term) were 18 times more likely to have a low birth weight baby as compared to those mothers who gave birth at 37 weeks gestation or more $(A O R=18.2 .95 \% C I=9.26-35.94)$. Similar findings were observed in Tamilnadu, Gondar and Iran ${ }^{11-}$ 13 .

Maternal nutrition was also associated with low birth weight in this study. Mothers with MUAC less than 23 $\mathrm{cm}$ were more than three times more likely to have a low birth weight baby than mothers whose MUAC was more than $25 \mathrm{~cm}$ (AOR 3.4(95\% CI: 1.38-8.60). Studies conducted in Africa and Asia support this finding ${ }^{6,23}$.

Furthermore, pregnancy induced hypertension was another factor associated with low birth weight in the current study. Mothers who had pregnancy induced hypertension were six times more likely to have low birth weight baby than those who did not $(\mathrm{AOR}=6.5(95 \% \mathrm{CI}=3.06-14.00)$.
This finding is consistent with the study done in Ethiopia, Western Maharashtra, Indian and china ${ }^{11,13,20,22}$.

This study has some limitations. First, the cross-sectional nature of the study does not confirm definitive cause and effect relationship. In addition, reports for some of the questions were history or encounters which are prone to recall bias. Finally, Although we have collected a wide range of factors associated with LBW in developing countries, we did not have data on other factors possibly associated with LBW such as maternal pregnancy diabetes, maternal psychopathology, and other genetic and environmental factors.

\section{Conclusion}

The prevalence of low birth weight was in line with WHO estimate of low birth weight for sub-Saharan Africa. Age of the mothers, income, pre-term, mid upper arm circumference less than $23 \mathrm{~cm}$ and pregnancy induced hypertension were factors associated with low birth weight. It is recommended to encourage the mother to give birth between the age range of 20 to 34 years, to prevent low birth weight. Nutritional counseling of pregnant mothers to have adequate weight gain $(1.5 \mathrm{~kg} /$ month in the last two trimesters) during pregnancy is also recommended. Furthermore, early detection and management of pregnancy induce hypertension is not compulsory.

\section{Competing interests}

The authors declare that they have no competing interests.

\section{Authors' contribution}

TA originated and wrote the proposal, participated in data collection, analyzed the data and drafted the paper. BAD revised subsequent drafts of the manuscript and approved the proposal. BAD wrote the manuscript. All authors read and approved the final version of the manuscript.

\section{Acknowledgement}

We would like to pass our gratitude to the Bahir Dar University for the approval of ethical clearance and technical support. We are very grateful for respondents all who participated in this study.

\section{References}

1. WHO, UNICEF: low birthweight: country, regional and global estimates. 2004.

African Health Sciences Vol 18 Issue 4, December, 2018 
2. WHO/UNICEF: Prematurity and Low Birth Weight. In.; 2009.

3. Zeleke BM, Zelalem M, Mohammed N: Incidence and correlates of low birth weight at a referral hospital in NorthWest Ethiopia. Pan African Medical Journal. 2012, 12:4.

4. Teklehaimanot N, Hailu T, Assefa H: Prevalence and factors associated with low birth weight in Axum and Laelay Maichew Districts, North Ethiopia: A comparative cross sectional study. International Journal of Nutrition and Food Sciences. 2014, 3(6):560-566.

5. Tema T: Prevalence and determinants of LBW in Jimma zone, SouthWest Ethiopia. East African Medical Journal. 2006, 83(7):366-371.

6. Assefa N, Berhane Y, Worku A: Wealth Status, Mid Upper Arm Circumference (MUAC) and Antenatal Care (ANC) Are Determinants for Low Birth Weight in Kersa, Ethiopia. PLoS ONE. 2012, 7:6.

7. World Health Organization Guide lines on optimal feeding of low birth weight infants in low and middle income countries. Geneva, Switzerland. In.; 2011.

8. Central Statistical Agency: Federal Democratic Republic of Ethiopia Central Statistical Agency Population Projection of Ethiopia for All Regions. 2013

9. Berihun Megabiaw Zeleke, Meseret Zelalem, Nuru Mohammed: Incidence and correlates of low birth weight at a referral hospital in NorthWest Ethiopia. The Pan African Medical Journal. 2012, 12(4).

10. Central Statistical Agency Ethiopia, ICF Internationalentral Statistical Agency: Ethiopia Demographic and Health Survey 2011. Addis Ababa, Ethiopia and Calverton, Maryland, USA: Central Statistical Agency and ICF International. In.; 2012.

11. Davoudi N, Khezri M, Asgharpour M, Khatami SM, Hoseinpour M, Azarian AA: Prevalence and Related Factors of Low Birth Weight in Mashhad, Iran. Iranian Journal of Neonatology. 2012, 3(2).

12. Dandekar RH, Shafee M, Sinha SP: Prevalence and risk factors affecting low birth weight in a district hospital at Perambalur,Tamilnadu. Global Journal of Medicine and public health. 2014, 3(2).

13. Zenebe K, Awoke T, Birhan N: Low Birth Weight \& Associated Factors Among Newborns in Gondar Town,
North West Ethiopia: Institutional Based Cross- Sectional Study. Indo Global Journal of Pharmacentical Sciences. 2014, 4(2):74-80.

14. Agarwal G, Ahmad S, Goel K, Kumar V, Goel P, Garg M, Punj A: Maternal Risk Factors Associated with Low Birth Weight Neonates in a Tertiary Care Hospital, Northern India. Journal of Community Medicine \& Health Education. 2012, 2:9.

15. Veloso HJ, da Silva AA, Bettiol H, Goldani MZ, Filho FL, Simoes VM, Batista RF, Barbieri MA: Low birth weight in Sao Luis, NorthEastern Brazil: trends and associated factors. BMC Pregnancy Childbirth. 2014, 14:155. 16. Ghani AEA, Mai H, Demmouche A Epidemiology of Low Birth Weight in the Town of Sidi Bel Abbes (West of Algeria): A Case-Control Study. Journal of Nutrition and Food Sciences. 2014, 4(3).

17. Fosu MO, Abdul-Rahaman I, Yekeen R: Maternal Risk Factors for Low Birth Weight in a District Hospital in Ashanti Region of Ghana. Research in Obstetrics and Gynecology. 2013, 2(4):48-54.

18. BenerA, Saleh NM, Salameh KMK, Basha B, Joseph S, Buz RA: Socio-demographic and consanguinity risk factors associated with low birth weight. Journal of Pakistan Medical Association. 2013, 63(5).

19. Sah RB, Regmi MC, Subedi L, Shah U, Jha NB: Burden of teenage pregnancies in Terai area of Eastern region of Nepal International Journal of Research in Health Sciences. 2014, 2(4):947-952.

20. Mumbare SS, Maindarkar G, Darade R, Yenge S, Tolani MK, Patole K: Maternal Risk Factors Associated with Term Low Birth Weight Neonates: A Matched-Pair Case Control Study. Indian Pediatrics. 2012, 49(1):25.

21. Viengsakhone L, Yoshida Y, Harun-Or-Rashid M, Sakamoto J: Factors affecting low birth weight at four Central hospitals in Vientiane, Lao PDR. Nagoya J Med Sci. 2010, 72(1-2):51-58.

22. Huang A, Jin X, Liu X, Gao S: A matched case-control study of preterm birth in one hospital in Beijing, China. Reproductive Health. 2015, 12(1).

23. Ververs M, Antierens A, Sackl A, Staderini N, Captier V: Which Anthropometric Indicators Identify a Pregnant Woman as Acutely Malnourished and Predict Adverse Birth Outcomes in the Humanitarian Context? PLoS Curr, 5. 